\title{
Os valores e o valor da moeda: hipóteses sobre a comensurabilidade e a monetarização do impacto de projetos sociais
}

\author{
Values and the value of money: hypotheses on the commensurability and monetization of \\ the impact of social projects
}

\author{
Eloisa Helena de Souza Cabral ${ }^{1}$ \\ Paulo de Tarso Muzy²
}

\begin{abstract}
Resumo
A experiência de monetarização de impacto de projetos desenvolvidos por organizações de interesse público ou por programas de responsabilidade social empresarial requer metodologia avaliativa que contemple os resultados expressos como fatos - ou mudanças imediatamente quantificáveis na vida das pessoas - e resultados expressos como valores - ou percepções de princípios e normas, comunicados ao longo dos projetos. O objetivo deste artigo é apresentar e discutir as hipóteses necessárias para a apropriação comensurável dos aspectos valorativos e factuais, considerando os significados sociais da moeda identificados nos circuitos de troca dos bens públicos envolvidos. A abordagem, que tem por referencial teórico as contribuições de H. Putnam e A. Sem. vale-se do diálogo com a sociologia econômica para construir indicadores mensuráveis do impacto. Como resultado, a monetarização explora o significado do impacto para a organização, em termos de custos e benefícios sociais; para os doadores, como medidas da responsabilidade social e valor agregado; e, para os beneficiários, como quantificação da mudança na percepção de valores e de atitudes. Como método para essa discussão, aplicamos esses argumentos à avaliação de um projeto social local, desenvolvido em Belo Horizonte-MG, mostrando que os valores podem ser incorporados como elementos mensuráveis e apropriados para a representação econômica do impacto.
\end{abstract}

Palavras-chave: Valores. Avaliação de impacto. Monetarização. Terceiro setor. Responsabilidade social.

\begin{abstract}
The experience of monetizing the impact of projects developed by public interest organizations or by corporate social responsibility programs requires an evaluative methodology that considers outcomes expressed as facts - or immediately quantifiable changes in people's lives - and outcomes expressed as values - or perceptions of principles and norms, communicated throughout the projects. This article aims to present and discuss the hypothesis needed for the commensurable appropriation of the factual and evaluative aspects, considering the social meanings of money identified in the circuits of exchange of public goods involved. The approach, that has as its theoretical framework the

Artigo submetido em 30 de abril de 2013 e aceito para publicação em 14 de novembro de 2013.

DOI: http://dx.doi.org/10.1590/1679-39518411

1 Professora adjunta da Universidade Federal de Lavras - Departamento de Administração e Economia; Doutora em Ciências Sociais - Sociologia pela Pontifícia Universidade Católica de São Paulo. Endereço: Campus Universitário, Caixa Postal 3037, CEP 37200000, Lavras - MG, Brasil. E-mail: elocabral@uol.com.br

2 Doutor em Física Teórica pelo Instituto de Física da Universidade de São Paulo; Diretor da Tempo Avaliação e Gestão Social Ltda. Endereço: Rua São José 261, apt. 132, CEP 04739-000, São Paulo - SP, Brasil. E-mail: ptmuzy@uol.com.br@uol.com.br
\end{abstract}


contributions by $\mathrm{H}$. Putnam and A. Sen, resorts to dialogue with the economic sociology to construct measurable indicators of the impact. As a result, monetization explores the impact's meaning to the organization, in terms of costs and social benefits; for donors, as social responsibility and added value measures; and, for beneficiaries, as a quantification of the changed perception of values and attitudes. As a method for this discussion, we apply these arguments to the assessment of a local social project, conducted in Belo Horizonte, Minas Gerais, Brazil, showing that fact and values indicators may be constructed to measure monetary aspects of the impact.

Keywords: Values. Impact assessment. Monetization. Third sector. Social responsibility.

\section{Introdução: O Mito e a Moeda}

Durante o verão do ano de 2011, enquanto o parlamento forjava alternativas para o futuro da Grécia como integrante da Europa, do outro lado da praça Syntagma, a Ágora contemporânea daquela manifestação pública sobre a crise, uma mostra artística era inaugurada na sede do Alpha Bank. A Myth and Coinage Exhibition: representations, symbolism and interpretations from the Greek mythology [Exposição Mito e Cunhagem: representações, simbolismo e interpretações da mitologia grega] apresentava a história da moeda grega como meio de comunicação e comércio. No primeiro edifício, havia valores humanos, culturas, modelos de desenvolvimento, interesses e capacidades mensurados por uma métrica, o euro, padrão monetário e garantia da representação da riqueza. No outro, mostrava-se a moeda - inerte como meio de pagamento, mas atuante como mídia do mito nas vitrines do museu -, persistente como testemunha das transações mercantis e como objeto artístico.

Desde sua origem, as moedas estampavam na face mercantil um valor de troca enquanto na outra face havia imagens de deuses, ou mitos codificando mensagens sobre os valores reconhecidos pelos gregos acerca de sua explicação do universo, da natureza, da vida e da expansão de seu poder e território. Na exposição, aprendia-se que em 575 a.c. o electrum stater, cunhado em Sardes, na Lídia, mostrava um leão, símbolo da casa real, lutando com um touro, similar àquele que pode ser encontrado ainda hoje na esquina de Wall Street. Suas 8,6 gramas de uma liga (electrum) de ouro e prata compravam, à época, uma dúzia de pés de porco (akrokolion) e simbolizavam a luta entre o poder do Estado e a liberdade do mercado, sob a confiança dos deuses.

A apreciação da Myth and Coinage relembra a pergunta de Paul Veyne (1983) - acreditavam os gregos em seus mitos? - à qual o autor responde afirmativamente, com ressalvas, reconhecendo que eles os diferenciavam da verdade histórica e da realidade da natureza, como narrativas imaginárias que ordenavam simbolicamente o mundo e que coexistiam com a história vivida de modo não contraditório, mas ilustrativo. Assim, a associação entre o mito e a moeda aproximava métricas e indicava determinada tangibilidade ao mito, possibilitando cogitar que a pergunta de Veyne poderia ser relida assim: qual o valor atribuído ao mito? Com certeza, os gregos valorizavam seus mitos também como elementos de coesão social e representação ideológica e nós, ainda, hoje refletimos sobre esses valores transmitidos e valemo-nos de suas representações para evocar nossas atitudes e valores. Os mitos transmitiam o que, modernamente, designamos valores, ou crenças e princípios comunicados, na forma mitológica que a cultura grega escolhera, induzindo comportamentos e modulando o significado das ações.

O debate contemporâneo na praça, no mercado, ou na mídia acerca da crise grega envolve decisões urgentes e consequências imprecisas, perdas estimáveis e perspectivas de vida. Fundamentalmente, envolve fatos e valores que coabitam a racionalidade, ambos observáveis em termos de alternativas e escolhas que as sociedades globalizadas devem exercer a partir de informações e significados. De modo semelhante, os gregos antigos expressaram esses fatos e valores em seu invólucro cultural, nas duas faces de suas moedas, antepondo mitos e dinheiro como expressões complementares da vida social. A pergunta de Veyne (1983) pode orientar-nos sobre nossas crenças no progresso econômico e na nossa capacidade de associá-lo ao desenvolvimento humano. 
Entre os dilemas contemporâneos, persiste a questão do risco da fratura social, global e localmente. O meio ambiente, as diferenças de gênero, a desigualdade, o radicalismo religioso, o terrorismo, a assimetria na educação, no trabalho, e o preconceito são faces da modernidade para as quais escolhemos representações contemporâneas em padrões de sustentabilidade, tolerância, solidariedade, cooperação e equidade, como valores sociais desejáveis. Seriam esses valores suficientes e necessários para se antepor à barbárie? O objetivo deste artigo é refletir acerca do valor social dos riscos que assumimos e do benefício de superá-los. Consideramos que ambos podem ser quantificados, inclusive monetariamente, para estimar as possibilidades e capacidades de enfrentá-los e comunicá-los, como faces de uma moeda. Como exemplo, referimo-nos aos projetos sociais, os quais se distinguem por pretender disseminar valores humanos e atingir resultados que afastem seus beneficiários das várias formas do risco.

\section{As Duas Faces da Moeda: Fato e Valor no Referencial Teórico da Avaliação}

O problema da monetarização, ou da expressão monetária dos resultados da avaliação do impacto, pode ser atacado sob duas perspectivas:

- A monetarização pode representar a redução dos valores humanos relevantes para os projetos a simples expressões imediatas de valor monetário; ou

- A monetarização pode possibilitar a identificação e incorporação de fatos e valores constitutivos do objeto avaliado, ampliando o significado do valor monetário do impacto.

A primeira alternativa sugere que identifiquemos o valor econômico de um objeto tratando-o como um bem mercantil e parte, metodologicamente, do valor econômico identificado em direção ao objeto que incorporará aquele valor. A segunda alternativa sugere que encontremos métricas que expressem os valores associados a esse objeto, ampliando seus significados, inclusive mercantis, parte metodologicamente das relações sociais nas quais o objeto comparece como bem valioso e estima esse valor.

Este artigo desenvolve a segunda abordagem, que poderia receber a designação de heurística, porque trata a monetarização como o instrumento experimental capaz de suscitar a explicitação dos valores e dos fatos, também econômicos, reconhecíveis nos processos considerados valiosos. A primeira perspectiva é considerada um momento metodológico, tecnicamente realizável, porém, subordinada à segunda.

Quando expressamos o valor de um bem por meio de uma quantidade de moeda, valemo-nos dela, em primeira aproximação, como um referencial para a troca, para o pagamento, para a equiparação contábil, para a estimação de uma dívida ou para a reserva de valor necessária para a obtenção futura do bem. A moeda, mesmo nessa acepção usual e imediata, representa, inclusive simbolicamente, um instrumento que permite a realização futura da posse ou a confrontação pretérita de bens, transmitindo no tempo a informação que codifica esses bens, de acordo com valores socialmente acordados.

A investigação da antropologia econômica (GRAEBER, 2011, 59) mostrou que não existem evidências empíricas de que, em sua origem, a moeda já se apresentasse como instrumento facilitador de trocas. Esta é uma função posterior que o dinheiro assume, associada ao advento da organização de transações e da produção. Em sua origem primitiva a moeda estaria ligada ao reconhecimento das dívidas assumidas em relações sociais nas quais valores como poder, gratidão, dever, confiança, dádiva, status social, eram simbolizadas. Também os historiadores das finanças (FERGUSON, 2009) reconhecem sua função financeira de materialização de dívidas e expectativa de crédito no nascedouro do sistema bancário, que na alavancagem de recursos dava forma econômica a valores, como a garantia e a confiança, vitais para o desenvolvimento e o estabelecimento dos mercados. Outra não é a razão da presença na moeda moderna da chancela dos agentes econômicos do Estado que a emite e se compromete a sustentá-la. É também neste 
sentido que se compreende a iconografia mítica presente na moeda grega, que orienta sua utilização e garante seu valor de troca.

A disciplina Sociologia Econômica (SMELSER e SWEDBERG, 2005; CARRUTHERS e ARIOVICH, 2010; ZELIZER, 1994) examinou a moeda como instituição social, desvendando sua natureza pretensamente fungível, ou moldável, contida no conceito imediato de dinheiro. Reconhecendo as determinações sociais que expandem aquelas acepções, mostrou-se que a moeda não está isolada de relações sociais não monetárias, pois ela transmite o valor acordado socialmente e adquire significados diversos com esses vínculos. A moeda excede sua expressão abstrata como coisa e assume características, ou significados, para seus possuidores, nas diversas relações econômicas, por exemplo, quanto à quantidade de valor que representa, a qualidade dos bens envolvidos, a finalidade dos pagamentos ou das reservas, a alavancagem do sistema financeiro, as identidades dos atores, desempenhando funções e estabelecendo valor.

Desde os clássicos Polanyi (2012) e Simmel (1978), encontramos estudos dos autores Appadurai (1986), Doyle (1992), Furnham e Argyle (2000), Fligstein (2001), Steiner e Vatin (2000), dentre os quais destacamos os brasileiros Martes (2009), Mondadore, Pedroso Neto, Leite et al. (2009), Abramovay (2004) e Vinha (2003), acerca da interação dos mundos econômico e social, que apresentam exemplos do que Zelizer (1994) denominou significados sociais da moeda. Na fronteira com o Direito (POSNER, 2010; NUSDEO, 2000), a Economia (OSTROM, 2002; NORTH, 1977, KAHNEMAN e KNETSCH, 1992), a Teoria das Organizações (BEN-NER e PUTTERMAN, 1998), também se aprecia a estrutura da expressão monetária e sua representação simbólica.

Particularmente, o exame do impacto de projetos sociais oferece um campo experimental (CABRAL, 2011a) para abordar a expressão de possíveis significados monetários dos bens de interesse público equivocadamente tratados como manifestações intangíveis e qualitativas, descritivas subjetivamente da realidade factual de seu entorno social. Como a esses bens não está adstrito um significado econômico imediato, sua monetarização exige um exercício de outro tipo, que parte desses significados, como hipóteses, e reconstrói a significação econômica.

Assim, em vez de considerar que a expressão monetária restringe o significado social mais amplo, ao impor uma métrica monetária, pode-se tratar a monetarização como o processo de descoberta de significados sociais que, traduzidos monetariamente, elucidam a presença de valores, antes considerados intangíveis e não observáveis e garante a expressão da informação econômica contida nos valores reconhecidos socialmente em um bem. Essa perspectiva de abordagem da monetarização contribui para a agregação de valor a partir da valoração de bens outrora desconsiderados, superando a visão imediata de que a moeda simplesmente reduz essa significação.

Segundo Zelizer (1994), Espeland e Stevens (1998), a monetarização identifica significados que caracterizam a circulação da moeda, expressa valor nas redes sociais, unifica informações e possibilita comparações, desde que realizada com cautela para não induzir simplificações estranhas à natureza dos agentes. Zelizer (2007) denominou circuitos de troca as estruturas sociais interativas que se envolvem homogeneamente na vida econômica, diferenciando-se tanto de modelos relacionais de dois indivíduos como de estruturas organizadas, como as firmas, as instituições e as redes.

O conceito de circuito é uma tentativa empírica de identificar vínculos sociais que não sejam estruturados institucionalmente nem modelados, mas reconhecidos na circulação dos valores. Para reconhecê-los, a autora sugere que se atente para o conjunto de relações sociais que os organiza; o compartilhamento de atividades ou valores implícitos nessas relações; o compartilhamento de significados; e uma fronteira que identifica membros. 


\section{Avaliação e Monetarização do Impacto de Projetos Sociais}

No caso dos projetos sociais, a asserção de intangibilidade dos benefícios é uma forma alienada de atribuição de valor, recusando-lhes a possibilidade de mensuração e comparação, que podem elucidar os valores tacitamente aceitos nos fatos. A monetarização dos benefícios diz respeito, então, à identificação das articulações nas quais transitam os bens valiosos determinados, imprimindo significado aos recursos econômicos envolvidos pelos vários públicos vinculados pelas organizações. É nesse sentido que essa abordagem almeja ser fiel ao conceito de embeddedness desenvolvido por Granovetter (1985), que está na origem da moderna sociologia econômica ao estimar aspectos precisos da imersão do mundo econômico no mundo social.

A monetarização do impacto, no sentido aqui delimitado, sugere que examinemos as expressões factuais e valorativas presentes nos problemas abordados nos projetos sociais. As expressões factuais compreendem as mudanças, decorrentes de situações usualmente mensuráveis, por exemplo, da melhoria da renda, da empregabilidade, do conhecimento, do preparo técnico. As expressões valorativas concernem à percepção, ao reconhecimento e à explicitação dos valores humanos considerados pertinentes, por exemplo, à cidadania, ao convívio, à tolerância, à organização, à coesão social, ao respeito e aos comportamentos individual e coletivo.

A monetarização é uma etapa final dos processos de avaliação de impacto cujo objetivo é atribuir valor monetário ao bem, considerando o conjunto de atributos valiosos que o encerram. É comum atribuir o significado monetário a objetos e bens enquanto fontes de recursos ou dispêndios futuros, realizáveis como possibilidades, aceitáveis, como perdas e passíveis de compensação como fatos previstos. Esse seria o percurso das metodologias de avaliação contingente (MITCHELL e CARSON, 2005); ele reflete os custos sociais do objeto examinado e informa de modo parcial acerca do valor socialmente atribuído ou da estimativa indireta de como ele é considerado valioso nos círculos sociais que o envolvem.

A nova perspectiva considera o valor atribuído à escolha e dialoga com Amartya Sen (1997), em seus estudos sobre a qualidade de vida, a necessidade metodológica de investigar não apenas indicadores realizados no estado de bem-estar, mas, sim, os valores relativos à capacidade, ou liberdade, de agir em direção da escolha valorizada - ou das capabilities - conceito estabelecido por Sen (1997) que preside a metodologia de avaliação (CABRAL, 2011a) aqui aplicada. Portanto, a monetarização excede a precificação mercantil e refere-se a um estado no qual os indivíduos fruem um bem público e se conectam por meio de valores considerados relevantes nessa consumação. E o impacto comporta uma dupla natureza, que se apresenta como medida de uma mudança operada sobre indicadores de fatos e indicadores de valores.

Esse problema relembra as ponderações de Serva, Dias e Alperstedt (2010) sobre a necessidade da reflexão epistemológica acerca da abordagem multidisciplinar, que faz da Administração uma arte integradora de saberes. Dentre os desafios que se apresentam à Administração como uma ciência social aplicada, está a demanda pela avaliação do impacto dos projetos desenvolvidos por organizações sociais, cooperativas, nos programas de responsabilidade social empresarial ou em parceria com organizações públicas. A metodologia de avaliação proposta por Cabral (2011a) vincula os fatos e os valores como componentes do impacto e associa resultados expressos por indicadores de fatos e metas alcançadas (p. ex., melhoria de renda; aprendizagem; preservação ambiental), a um conjunto de valores (p. ex., participação; respeito; uso e valoração do tempo; confiança) expressos por indicadores de mudanças de atitude, estimação e percepção de valores. Essa abordagem se fundamenta no tratamento do Terceiro Setor como um espaço público dotado de atributos e considera que os fatos realizados e os valores transmitidos vinculam-se às Expectativas, Necessidades, Capacidades, Interesses e Representações (ENCIR) e que identificam os públicos constituintes acessados pelos projetos (CABRAL, 2011a). O conceito de públicos constituintes possibilita o reconhecimento dos diversos grupos sociais que se diferenciam pelas ENCIR, associando-se em termos dos valores relevantes que os projetos comunicam. 
Esse debate reporta ao exame epistemológico do lugar nos valores na racionalidade. Putnam (2002) denominou dicotomia fato/valor o engano de submeter os valores a uma posição descritiva e abordar os fatos como determinantes exclusivos para a definição e identificação dos estados assumidos em um processo. A prática da avaliação desses estados, no caso dos projetos sociais locais, oferece um campo experimental fértil para o teste e a generalização de procedimentos que possibilitem inferir e mensurar a validade dos vínculos sociais entre os fatos e valores, pois essas organizações transmitem em seus projetos a hibridização do espaço público de sua atuação, a diversidade de seus públicos constituintes e a vinculação entre fatos alcançados e valores almejados no impacto de suas ações.

\section{Avaliação e Complementaridade dos Juízos de Fato e de Valor}

Valores são princípios e normas que orientam e refletem ações e comportamentos, induzindo-os e assumindo representações sociais simbólicas que os comunicam estabelecendo redes e vínculos sociais (DWORKIN, 1977; PARSONS e SHILS, 1951; HONNETH, 1995; RAWLS, 1971). Sua inclusão nas experiências avaliativas possibilita identificar os atributos específicos que participam da construção de indicadores valorativos, como: ponderação; referencial de maximização; indeterminação de causas e efeitos; $e$ unificação de manifestações.

Como exemplo, tome-se a afirmação: a temperatura do ambiente é 30 graus centígrados, incontestável como fato, pela mensuração de um termômetro, e compare-a com a afirmação faz calor neste ambiente, que expressa uma sensação. Quando afirmamos uma expressão numérica para a avaliação da temperatura do ambiente, tratamos de uma informação cujo significado transmite, por se tratar de um número, as noções de cardinalidade e ordinalidade inerentes ao número. A cardinalidade dá conta da quantidade em si envolvida na medida. Por exemplo, o número 30 indica o conjunto que possui 30 elementos. Complementarmente, a ordinalidade indica, nesse caso, a propriedade do número 30 ser o trigésimo elemento de uma sequência ordenada.

Quando afirmamos uma expressão valorativa faz calor, transmitimos o significado da experiência e do campo das possibilidades, inerentes também ao mundo empírico, no caso, referindo-se às diversas percepções da sensação térmica. A indeterminação de causas e efeitos indica que não existe, nessa afirmação, a determinação precisa sobre suas causas ou consequências, pelo contrário, os valores apresentam-se como referências construídas de maneira suficientemente ampla para abrigar uma variedade de possibilidades e incluir também uma variedade de alternativas de sua realização, unificando as manifestações de fatos. Essas propriedades são centrais para os juízos de valor, sugerindo um princípio de causalidade do enunciado, de modo que ele não se compromete com os pressupostos necessários nem se submete a decorrências determinadas, garantindo sempre a potencialidade da sua aplicação e as possibilidades de suas ocorrências. Como referencial de maximização, os valores indicam estados a ser alcançados empiricamente, o que, no exemplo, pode ser tratado como o padrão de conforto térmico. O atributo ponderação garante a possibilidade de composição do valor, com outros valores, para sua efetivação e sugere que a sensação não é determinada e definitiva, mas pode ser vinculada a outros valores para a avaliação do conforto térmico do ambiente.

Sob o aspecto teórico, os quatro atributos se articulam, de modo que a consideração dos valores garante um referencial do exame do campo das possibilidades, das liberdades de realização das ações investigadas, preservando a escolha máxima sobre um acervo de alternativas existentes, resguardando o ingrediente de liberdade do dever-ser passível de hierarquização e composição com outros valores, de modo variável, convergente e ponderado.

Sob o aspecto prático, as características dos valores dialogam consistentemente com os requisitos apresentados por Sen (1999) acerca da relação entre meios e fins, que deve ser observada na avaliação, considerando a possibilidade prática de adequação múltipla e alternativa dos meios às finalidades. A 
possibilidade de maximização é tratada por Sen (1997) ao mostrar que as escolhas se dão entre possibilidades reais, que refletem as parcelas de informação disponíveis e incompletas, que compõem os estados avaliados a partir da variedade ponderada por valores. Assim, enquanto a afirmação factual da temperatura traz a informação parametrizada que caracteriza o ambiente, a afirmação valorativa possibilita a intensificação e a escolha do melhor conforto, que pode ser atendida a partir de várias alternativas implícitas nessa intensificação.

De acordo com Sen (1997), a atribuição de valor a um bem e o ato de sua escolha não são equivalentes, do ponto de vista lógico, sendo um exemplo possível a questão: "O que possui valor para mim?". A resposta não será sempre "o que eu escolho", porque a escolha é feita a partir de um campo de possibilidades realizáveis. Porém, se perguntarmos "o que eu escolho?", a resposta óbvia é "o que possui valor para mim". Pois a escolha supõe a identificação dos valores presentes e ponderados na situação de fato. Os atributos que possibilitam o ato da escolha, portanto, são a ponderação do valor, que examina as alternativas dadas e unificadas e escolhe a que tem valor intensificado pela possibilidade de sua realização maximizada. Portanto, de acordo com a variedade de causas e efeitos, a decisão deve considerar a incerteza. Esses atributos contribuem para o esclarecimento do lugar dos valores na avaliação dos pontos de vista teórico e prático, que confluem para a identificação do atributo de ponderação, como condutor da prática de composição reflexiva, a partir da variabilidade dos estados avaliados, considerando as decisões necessárias com base nas informações parciais e disponíveis.

Putnam (2002), em sua argumentação para demonstrar o engano propiciado pela dicotomia fato/valor, tomada como tese epistemológica, mostra que existe, efetivamente, uma distinção entre fato e valor, reconhecida como uma partição ordinária entre aquilo que se constata e aquilo que se estima. Porém, essa distinção não tem o condão lógico de produzir uma dicotomia que antagonize epistemologicamente os fatos e os valores como pertinentes a realidades distintas, ou que priorize os juízos de fato e desconsidere os juízos de valor, tomando-os por imponderáveis ou tratando o subjetivo como o não observável ou, de modo contrário e antagônico, que assuma os juízos de valor como garantia e padrão de algum pretenso valor moral ou teleológico superior para o exame dos fatos.

Recorrendo aos exemplos das afirmações anteriores, a temperatura do ambiente é 30 graus centígrados e faz calor neste ambiente, o que as torna diferentes, enquanto expressões de diferentes signos, não pode torná-las antagônicas, porque sua validade só tem sentido se expressa, seja por termômetros ou sensações, construídas, ou experimentadas, por seres humanos no exercício de suas finalidades e objetivos. Ao assumir a validade da primeira, porque podem dois indivíduos concordar com o termômetro, não se pode determinar a invalidade da segunda apenas porque esses indivíduos podem discordar sobre sua intensidade. Em primeiro lugar, não existe dicotomia, pois se trata de juízos baseados em referenciais diferentes acerca de um objeto, no caso, o ambiente; em segundo lugar, porque qualquer prioridade de um juízo seria imposta como tese e não como consequência das afirmações; e, em terceiro lugar, porque não estão em questão definições precisas e excludentes de fato e valor, mas noções parciais e complementares, que agregam informação parcial ao objeto, naturalmente dotado de incertezas.

Putnam (2002, p. 19) oferece as bases epistemológicas para a complementaridade dos juízos e mostra que a almejada dicotomia é uma tese que separa inconsistentemente a ética e as matérias de fato, os julgamentos analíticos e os sintéticos, não apenas distinguindo-os, porque são distintos, mas os tratando como incomensuráveis e sugerindo pretensa neutralidade abstrata, que nada mais é do que a reafirmação recuperada da tese que prioriza um juízo como fonte de racionalidade, considerando-o prova e juízo simultaneamente. No que concerne à avaliação, Putnam $(2002$, p. 46) ressalta a contribuição de A. Sen para vincular, no campo da economia, o julgamento do que é considerado valioso por um indivíduo como a expressão factual do resultado dos estados alcançados para estimar o bem-estar. É nesse sentido que as experiências avaliativas de A. Sen esclarecem a vinculação de fatos e valores e repõem a consideração ética no domínio econômico, estabelecendo para além das consequências da escolha a liberdade de escolher, como foco do processo avaliativo. Esse raciocínio sobre a pretensa dicotomia fato/valor e a falácia de assumi-la, 
possibilitam explicitar, no centro do processo avaliativo, o conceito de capabilities, como as liberdades ou o conjunto de liberdades, que determina a fruição das funcionalidades realizáveis na vida social.

Seguindo o exemplo citado, pode-se afirmar que é a liberdade de fruir o conforto térmico de um ambiente que unifica as parcelas de informação contidas nas afirmações avaliativas acerca da temperatura de fato e da sensação térmica comparativa, reunindo condições para que o indivíduo se pronuncie sobre fatos e valores. Se avaliarmos o bem-estar do indivíduo, por meio do indicador de conforto térmico do ambiente, devemos investigar sua liberdade de fruição, único sentido da consideração da existência e da apropriação humana do ambiente confortável. Considerar essa liberdade, tecnicamente, significa agregar indicadores de fato e de valor, comensurando-os, reconhecendo as hipóteses que possibilitam essa comensurabilidade e reproduzem a valoração do conforto térmico como estado considerado valioso e assumido pelos indivíduos.

Não há princípio exclusivo de rigor inerente às afirmações unilateralmente. $\mathrm{O}$ risco da admissão da excludência dos juízos de fato em relação aos juízos de valor é assumir, em um ou outro caso, um referencial único da racionalidade, recaindo do engano de desconsiderar a parcialidade da informação e assumindo as determinações que emanam apenas de um dos polos como ingredientes de decisão. A insistência na dicotomia é o engano de atribuir significância exclusiva aos fatos ou, no outro extremo, o de considerar os valores em si, como detentores únicos de critérios de realidade.

Por exemplo, a consideração de valores relevantes como padrão único da investigação produziu as alegações que vitimaram Galileu Galilei (1564-1642) e tinham por suposto que o físico desenvolvia abordagens quantitativas acerca de uma pretensa harmonia inacessível ao número e alcançada apenas pela via da fé. No campo das ciências naturais, essas questões são superadas, por exemplo, com Penrose (1976), e o reconhecimento da estética na construção de padrões matemáticos que antecipou a descoberta dos quase cristais; ou com a argumentação de Prigogine e Stengers (1986), que identificaram na métrica temporal a possibilidade de reagrupar uma nova aliança epistemológica, necessária para dar conta dos fenômenos físicos irreversíveis e probabilísticos; ou, ainda, com Mandelbrot (1982), que inovou o tratamento da desordem e suas formas, com aplicações reconhecidas na economia, considerando as diferenciações sutis da aspereza (roughness) e da representação gráfica contidas nas estruturas reais e incorporando-as na geometria de seus modelos fractais.

Entretanto, persistem, nas ciências sociais aplicadas, insistentes manifestações da dicotomia fato/valor, que exigem esforços práticos de superação, como o empreendido por J. Stiglitz (2009) ou por J. Stiglitz, A. Sen e J.-P. Fitoussi (2010), que coordenaram os debates para a construção de um índice planetário que reagrupasse indicadores de desempenho econômico e progresso social, com a inclusão de medidas de uso do tempo. Esses indicadores se mostraram capazes de apreender a qualidade (e o valor) dos processos temporalizados, por mensurar a dedicação dos indivíduos a uma tarefa, que, no caso em exame, do IDH, tratava-se da educação. Stiglitz (2009) ao examinar quão desigual pode ser uma sociedade, reafirmou a primazia dos processos sobre os resultados imediatos, na mesma direção apontada por Sen, por meio do conceito de capability. No que concerne à teoria da avaliação, reproduz-se situação semelhante, pelas razões resumidas e criticadas na conferência da American Evaluation Association (2011), Values and Valuing in Evaluation [Valores e Valorização em Avaliação], sob a forma de quatro impedimentos: valores não são observáveis; valores não explicam os processos que os incluem; não há consenso teórico acerca de como os valores modulam os comportamentos; considerar valores traz problemas de comensurabilidade para as medidas.

As experiências de monetarização em projetos sociais possibilitam enfrentar, principalmente, os dois últimos preconceitos, percorrendo o caminho inverso ao da argumentação, desconstruindo experimentalmente o pretenso valor único da moeda e reconhecendo nela, por meio da recuperação de seus valores ou da semiótica de seu valor, os significados que ela pode transmitir a partir da incorporação de sua funcionalidade em um campo no qual parece pouco requisitada.

No caso da monetarização do impacto, essa abordagem toma a inter-relação entre os fatores econômicos e os valores para admitir a possibilidade de reconstruir em moeda uma quantificação legítima que identifique e 
estime parcelas ocultas da informação contida nos vínculos sociais. É fundamental ressaltar que essa monetarização não se confunde com qualquer tentativa de precificação mercantil, ou contábil, do impacto, mesmo porque o espaço de fruição do bem público não é exclusivamente o setor mercantil, mas o espaço público, híbrido e intermediário entre o Estado, o mercado e as sociabilidades, no qual ele é disponibilizado como benefício.

Assim, podemos designar, sem perda de generalidade, como valor social o resultado da incorporação das dimensões comensuráveis de fatos e valores no impacto. Essas dimensões mostram-se historicamente dissociadas (SIMMEL, 1978; ZELIZER, 1994) e sua recomposição deve ser feita sem incorrer no risco da comodificação ou de um cash nexus que as desumanize. Por outro lado, a monetarização é um esforço pertinente e não exclusivo que agrega informação e significado ao benefício e indica a possibilidade de comparação com os custos sociais, explicitando-o e valorizando o benefício, por meio de significados inerentes à moeda como construção social. Assim, a monetarização não prescinde de, nem substitui, outras métricas complementares que possam dar conta da significação do impacto, tornando-se instrumento avaliativo, ao lado de outros, útil para a interpretação e comunicação dos benefícios.

\section{Metodologia da Avaliação e Apropriação de Fatos e Valores}

A discussão acerca da superação da dicotomia fato/valor complementa as justificativas apresentadas por Cabral (2011a) em sua metodologia de avaliação, em que encontramos aplicações experimentais e o método de apuração de valores, de desenvolvimento de indicadores, incorporando descrições valorativas e factuais e seguindo preceitos de comensurabilidade e parcialidade da informação, a criação de índices e o cálculo de impacto. Apresentamos, a seguir, os resultados de monetarização sugeridos na avaliação de impacto do projeto Portas Abertas (CABRAL, 2011b) de apoio aos jovens em situação de risco, desenvolvido pela Fundação Guimarães Rosa (FGR) de Belo Horizonte-MG.

A FGR acessa recursos sociais diversos e pretende disseminar valores de respeito, uso do tempo, disciplina, entre outros, realizando ações educativas e esportivas, após o horário escolar, utilizando instalações públicas compartilhadas com a Polícia Militar. A organização tem por hipótese que seus valores institucionais garantem o afastamento do risco social e ocupação positiva do tempo ocioso. Sua principal fonte de apoio é a Polícia Militar, cujos equipamentos e instalações, em um quartel urbano, são utilizados para integrar os jovens em risco e os agentes públicos.

O projeto tinha 5 anos de existência, na data da investigação, e atendia aproximadamente 200 indivíduos; contava e conta com apoio e doações de empresas e pessoas físicas, além das contribuições dos instituidores e da Polícia Militar. Não há aporte de recursos financeiros públicos.

A avaliação de impacto do projeto iniciou-se com a construção do Mapa de Bens Públicos (CABRAL, 2011a) para a identificação dos valores e fatos a ser incorporados nos indicadores. Esse instrumento identifica os valores relevantes e os relaciona às práticas que os transmitem. Questionários aplicados a grupos de tratamento e controle aleatório possibilitaram a criação de índices para monitoramento do impacto. A avaliação examinou um conjunto de indicadores (frequência e rendimento escolar, valores da educação, da participação, da cultura pública, do acesso e valores institucionais, imagem institucional, confiança, sustentabilidade econômica, ocupação do tempo, uso negativo do tempo, uso positivo do tempo, comprometimento de renda, qualidade do entorno, uso de drogas lícitas, uso do corpo, segurança, gravidez adolescente, violência, estabilidade da família) que, submetidos à análise de componentes principais, resultou em um índice composto por 7 dimensões (valores do jovem; valores da família; educação; defesa social; estabilidade familiar; sustentação econômica; imagem institucional).

O processo avaliativo ocorreu em 2011, quando foram aplicados questionários com 105 quesitos (CABRAL, 2011b) a todos os 147 jovens participantes (grupo de tratamento censitário) e às suas respectivas famílias 
(outros 147 questionários). Foi constituído um grupo de controle aleatório com 89 indivíduos e suas respectivas famílias, sorteados entre residentes na região do projeto que não participavam dele, mas guardavam semelhança nas variáveis características (sexo, idade, escolaridade, local, situação econômica, situação social, situação familiar) com o grupo de tratamento. O questionário consistia em questões fechadas, na maioria das quais o respondente apontava uma nota em uma escala Likert de 6 pontos, mensurando sua concordância com afirmações, as quais, agregadas, compunham os indicadores. Foi criado um índice de impacto social (ISFGR) como média simples dos indicadores. Um teste de hipóteses (t-test para igualdade de médias, com $95 \%$ de confiança) apontou a diferença significativa das médias do grupo de tratamento e do grupo de controle para o índice. Foram realizados testes para estimação de médias ponderadas a partir de análises de regressão e fatoriais, porém, a média simples mostrou-se mais resolutiva. A análise fatorial (principal axis) possibilitou a extração de 7 fatores com índice de Cronbach superior a 0,82, atestando consistência interna (reliability) suficiente. A análise de variância (ANOVA confirmatória) garantiu, com 95\% de confiança, os resultados de igualdade de médias, bem como estudos de regressão apontaram modelos de dependência confirmatórios para os fatores principais.

A análise do impacto mostrou que o grupo de tratamento melhora em 8,33\% sua proteção ao risco social, em relação a um grupo de controle aleatório. É esse impacto que se almeja monetarizar, considerando-o expressão empírica comensurada da realização da missão institucional, na qual coexistem fatos e valores.

\section{Monetarização e o Valor do Impacto}

Sob a perspectiva da monetarização, esse impacto reflete a criação de valor social, a partir do custo social da produção do bem público proteção social. A estimativa do custo social segue a apropriação contábil dos custos diretos, indiretos, de oportunidade, doações, trabalho voluntário e ativos imobilizados, custos administrativos e de parcelas de tempo dedicadas que incidem sobre os diversos públicos e foi estimada, em valores de março de 2013, em $\mathrm{R} \$ 1.519 .562,00$, dos quais apenas $\mathrm{R} \$ 257.406,00$ eram, anteriormente à avaliação, reconhecidos como despesas orçamentárias do projeto, efetivamente planejados e realizados, excluindo, portanto, todas as contribuições indiretas, voluntárias e de oportunidade

Para estimar o valor econômico associado ao bem público produzido, a primeira previsão necessária é aquela do valor da proteção social, em termos compensatórios, considerando o custo para a sociedade da incidência no risco social que ela pretende superar com a proteção oferecida. Para realizá-la, baseamo-nos na pesquisa Jovens em risco no Brasil, do Banco Mundial (2003), que oferece uma estimativa do custo do risco social. De acordo com esse estudo, que se afirma conservador em suas estimativas, o comportamento de risco induz custos sociais para a família, que socorre o indivíduo; para o Estado, que previne o risco e pune o indivíduo; e para o indivíduo, que deixa de ser remunerado convenientemente. São considerados custos relativos aos seguintes comportamentos de risco: abandono da escola; desemprego; gravidez de adolescente; HIV/DST; abuso de álcool; abuso de drogas; e crime e violência. O estudo propõe critérios para estimar os valores econômicos em função do impacto privado ou público, que permitem inferir o custo do risco social por indivíduo de até $\mathrm{R} \$ 1.836 .772,00$, em valores de março de 2013. Escolhemos uma medida mais conservadora ainda, computando apenas os custos públicos com abandono escolar, desemprego, HIV e crime, e custos privados, com abandono da escola, desemprego, gravidez, abuso de álcool e drogas. Excluímos os custos privados com crime e violência e com HIV/DST, pois é em relação a eles que o estudo aponta mais fragilidade dos dados disponíveis; sua apropriação exige maior número e abrangência de hipóteses; a população atingida pelo projeto, na eventualidade da evidência de HIV/DST, recorre ao Poder Público e não necessariamente arca com esses valores; e os custos privados com crime e violência envolvem o cálculo do valor da vida, para o qual, naquela situação, não temos dados disponíveis de comparação. Portanto, a monetarização realizada se vale, em primeira aproximação, de parâmetros associados ao custo social assumido pelo setor público e ao custo privado do comportamento de risco, no que diz respeito à escola, ao emprego, à gravidez, ao uso de álcool e drogas, como hipóteses que podem ser suportadas por nossos dados. 
Considerando estas últimas dimensões, atingimos o valor de $\mathrm{R} \$ 458.323,00$ (março de 2013) como total do risco social incidente por indivíduo e como parâmetro para orientar a monetarização do benefício social criado.

O valor econômico do impacto é obtido considerando que a melhoria de $8,33 \%$ na proteção social dos indivíduos permite apropriar economicamente a mesma porcentagem de 8,33\% do valor do risco social, como um valor que a sociedade tem expectativa de deixar de gastar, em virtude do afastamento das condições valorativas do risco. Trata-se, então, de calcular o produto de três fatores: o impacto social do projeto $(8,33 \%)$, que aporta a contribuição comensurada das medidas de fatos e de valores; o valor do risco social por indivíduo (R\$ 458.323,00), que aporta a contribuição do significado econômico compensatório; e o indicador de escala, dado pelo número de beneficiários impactados, que aporta a mensuração da escala do projeto.

A quantificação de beneficiários sempre é um ponto crítico das avaliações, seja por deficiência de registros, seja por critério para eleição ou exclusão dos indivíduos que participam da apropriação do benefício, seja pela indeterminação de prazos, tempo de permanências, nível de recepção do benefício, entre outros fatores próprios da gestão. $\mathrm{O}$ valor econômico reflete a escala local desses projetos, que os diferencia singularmente das avaliações de políticas públicas, as quais atingem escalas regionais ou nacionais e podem ser tratadas como universais e demandam outras formas de avaliação. No caso do projeto investigado, devemos refletir sobre o fato de não se apresentar um período fixo para a formação do beneficiário, tratando sua participação em função de pertinência à faixa etária. Para a estimativa do conjunto de beneficiados, pode-se escolher entre duas alternativas, definidas a partir da interpretação do valor médio do impacto apurado. Como o impacto de $8,33 \%$ foi apurado considerando o valor médio alcançado pelo grupo do projeto, pode-se tratar esse valor médio como um padrão a ser atingido pelos indivíduos; ou, de outra forma, considerá-lo como propriedade estatística do grupo estudado.

No primeiro caso, a abordagem é mais conservadora, pois apenas indivíduos que superarem esse padrão deveriam ser considerados para estimar o valor social do benefício. Essa seria uma visão mais gerencial do projeto, válida para propor metas ao gestor. Ela se fundamenta em uma concepção individualizada do benefício que considera o cálculo do impacto para cada membro do grupo como um processo de monitoramento de seu desenvolvimento. Seguindo essa premissa, 79 dos 147 indivíduos beneficiados estão acima da média. Para o segundo caso, a estimativa é mais ousada, pois trata o benefício como uma propriedade do grupo e que se realiza para todos os indivíduos, indistintamente. Assume-se uma visão que prioriza os aspectos sociais da coesão grupal e se fundamenta na concepção coletiva do benefício garantida no significado matemático da média como parâmetro estatístico descritivo do grupo. Seguindo essa premissa, podemos considerar os 147 indivíduos como a totalidade do grupo que se beneficia do projeto.

A Tabela 1 apresenta os resultados monetários desses dados, que são habitualmente estabelecidos nas avaliações de impacto a partir de metodologias contábeis disponíveis de análise financeira de projetos (CONTADOR, 1997).

Tabela 1

Monetarização do impacto dos benefícios (valores de março de 2013)

\begin{tabular}{|l|c|}
\hline Impacto & $8,33 \%$ \\
\hline Custo social & $\mathrm{R} \$ 1.519 .562,00$ \\
\hline Valor do risco social (por indivíduo) & $\mathrm{R} \$ 458.323,00$ \\
\hline
\end{tabular}


Cont. da Tabela 1

\begin{tabular}{|l|c|c|}
\hline Alternativa & Gestão & Social \\
\hline Número de beneficiários & 79 & 147 \\
\hline Valor do impacto (grupo) & $R \$ 3.005 .223,00$ & $R \$ 5.591 .998,00$ \\
\hline Taxa de retorno & $97,7 \%$ & $268 \%$ \\
\hline Retorno por R\$ 1,00 acessado pela FGR & $R \$ 1,97$ & $R \$ 3,68$ \\
\hline Custo social por indivíduo & $R \$ 19.234,00$ & $R \$ 10.337,00$ \\
\hline Valor do impacto individual & \multicolumn{2}{|c|}{$R \$ 38.040,00$} \\
\hline
\end{tabular}

Fonte: Elaborado pelos autores.

A leitura dos dados, com os significados implícitos apontados, permite afirmar que o projeto causa um impacto econômico equivalente a $\mathrm{R} \$ 38.040,00$ na vida dos participantes, afastando-os em 8,33\% do risco social suposto. Sob a perspectiva da gestão de uma meta, esse impacto pode ser realizado a um custo individual de R \$ 19.234,00, com um retorno econômico de $99 \%$, em 5 anos, considerando a aplicação que a sociedade realizou. Sob a perspectiva do grupo atendido, o impacto pode ser obtido a um custo menor, de R\$ $10.337,00$, com um retorno econômico de $269 \%$, no mesmo período. Considerando uma taxa de desconto de 5\% ao ano (VALENTIM e PRADO, 2008) para comparar os períodos de execução do projeto, pode-se afirmar que, considerado um bem público, o projeto apresenta um valor social líquido, análogo ao conceito contábil de valor presente líquido, equivalente a $\mathrm{R} \$ 1.497 .530,00$. A monetarização possibilita afirmar que os públicos constituintes realizaram a produção de bens públicos de proteção a um custo social de $\mathrm{R} \$$ 1.519.562,00, cujo valor social do impacto causado por sua fruição está estimado entre $\mathrm{R} \$ 3.005 .223,00$ e R \$ $5.591 .988,00$.

Vale, agora, fazer uma digressão acerca de outros cálculos que os dados suscitam. A partir do uso do valor social do risco, ingressa-se em um ambiente hipotético que exige cautela para ser interpretado e essa interpretação não pode ser feita imediatamente sem o concurso dos esclarecimentos que a reflexão sociológica possibilita. Nesse sentido, é importante ressaltar que a taxa de retorno econômico, de $99 \%$ no período de vida do projeto, indica a razão, ou parcela de valor, magnitude, ou quantidade da representação em moeda que retorna da aplicação social por meio do projeto. Assim, ela possibilita conjecturar que a cada real aplicado no projeto a sociedade se beneficia de uma suspensão mínima de gasto da ordem de $\mathrm{R} \$ 1,99$. Outras medidas podem ser desenvolvidas. Por exemplo, o cálculo da taxa interna de retorno (TIR), ou taxa de juros retornados pelo projeto, que mede a eficiência, ou a qualidade da aplicação e pode servir para comparações entre outros projetos. Tecnicamente, a TIR é obtida por meio da taxa anual de juros retornados pelo projeto e mensura a produção de valor que pode ser fruída, aproveitada no investimento de um capital. Ela considera despesas e receitas anuais e indica a taxa de juros que produz um valor presente líquido nulo, igualando os custos e os benefícios. Valores expressivos de TIR, superiores aos juros de mercado, indicam que o investimento adiciona valor ao empreendimento, o que tem correspondência conceitual com os aspectos metodológicos que assumimos. Cercando-nos de evidentes cuidados interpretativos, é possível realizar o exercício de cálculo da TIR para a abordagem mais conservadora do projeto, obtendo uma taxa de juros de $71 \%$ ao ano. A expressividade desse valor deve ser comparada com estudos econômicos de projeto, que têm como benefício a geração de emprego ou a melhoria salarial de jovens no primeiro emprego e atingem TIR da ordem de 17\%. Outros estudos, que envolvem desenvolvimento de comunidades e apropriam, além da geração de renda, medidas de comportamento e de benefícios sociais mais abrangentes, apontam TIR da ordem de $95 \%$ em 2 anos.

Assim, a medida quantitativa do retorno econômico é obtida por meio da taxa de retorno e a medida qualitativa é obtida pela taxa de juros. Porém, é preciso ter em mente que, para o cálculo dos custos e para a 
valorização dos benefícios do projeto, agrega-se a contribuição de custos sociais e de mudança na percepção de valores. Nesse sentido, o juro calculado é a taxa de reprodução desses valores e bens públicos e não uma taxa de juros do capital. Esses números requerem cautela para sua abordagem, pois se trata de quantificar expressões da vida social e não de bens de mercado, sujeitos a outras preferências. Eles servem como referências comparativas e especulativas, sujeitas às hipóteses e à interpretação dos indicadores sociais em sua apreensão de valores sociais e fatos, sem pretender que um ou outro retenha alguma forma de definição soberana da realidade. Por exemplo, a apropriação do retorno econômico (quantitativo) ou a criação de valor (qualitativo) é um fato social que supõe, prioritariamente, escolhas e não um fato mercantil que interessa apenas ao grupo que absorve o recurso e trata suas consequências sociais apenas como externalidades.

\section{Monetarização, simbolismos e circuitos de troca}

Em relação à percepção do fluxo dos valores monetários pelos indivíduos, o exame da disponibilidade de comprometimento de renda dos beneficiários com o projeto indicou que, para uma renda média, em março de 2013 , de $\mathrm{R} \$ 826,00$, as famílias beneficiárias estão dispostas a empenhar, em média, o valor mensal de $\mathrm{R} \$$ 38,00 , ou $\mathrm{R} \$ 456,00$ anuais, para participar do projeto, comprometendo até $4,60 \%$ de sua renda média. Esse comprometimento é equivalente à metade do empenho de renda média com transporte urbano nos grandes centros para um indivíduo com essa faixa de rendimento.

Porém, a quantificação apresentada possibilita examinar os aspectos sociológicos sugeridos por Zelizer (2007) acerca dos circuitos de troca. Os valores monetários apresentados na Tabela 1 foram obtidos apropriando-se da vinculação de valores relevantes para os públicos constituintes e de fatos associados, e a monetarização é a chave para a interpretação da dinâmica social que vincula esses indivíduos. Podemos, portanto, responder à questão inicial acerca da circulação da moeda enquanto valor de face e símbolo.

Os valores da Tabela 1 movimentam-se em 3 circuitos de troca, que podem ser identificados, a partir de entrevistas, de exame documental e de interpretação dos indicadores obtidos nos questionários, considerando os públicos constituintes. Em cada um dos circuitos de troca, materializam-se as expressões do fluxo de moeda trocada no processo e da sua significação social, constituindo, portanto, duas métricas distintas. A primeira, reconhecida pelo grupo e estimada como o valor imediato associado à sua intervenção no projeto, indica a realização econômica percebida como desembolso, ou troca, fungível no ato que organiza aquele grupo. A segunda, indicada pela monetarização, leva em conta a ampliação proporcionada pela consideração dos valores, desvenda e atribui significado ao conjunto dos públicos e realiza-se na expressão de suas respectivas ENCIR. Assim, encontramos:

- O circuito organizacional está constituído pela organização (FGR) que empreende o projeto e articula com seus parceiros organizacionais imediatos (Polícia Militar e organizações parceiras) sua operação. Nesse circuito, os indivíduos reconhecem, como a primeira métrica, o valor orçado de R \$ $257.406,00$ e sobre ele apontam suas realizações, comunicam seu trabalho e reconhecem explicitamente sua intervenção social e seus papéis. Esse valor imediato, associado ao projeto, pode ser tratado como a parte visível, contábil, orçamentária e desembolsada, apenas pelas organizações, no processo, sem a consideração dos custos indiretos, de oportunidade e tampouco dos custos que incidem sobre outros públicos. A segunda métrica, exposta pelo processo de monetarização indica o valor do custo social de $\mathrm{R} \$ 1.519 .562,00$, realizado com o concurso da capacidade organizacional de acesso da organização instituidora na sociedade. Esse valor parametriza o custo da transação social desenvolvida pela organização na execução do projeto.

- O circuito social dos doadores é constituído pelos indivíduos que doam tempo (voluntários), dinheiro ou bens materiais. Esses indivíduos estão vinculados episodicamente ao processo pelo ato de doação e desconectados entre si, de modo que reconhecem uma primeira métrica igualmente visível, no valor de $\mathrm{R} \$ 81.431,00$, na totalidade dos valores doados. A segunda métrica projeta o valor do risco 
social, de $\mathrm{R} \$ 458.323,00$, como a estimativa compensatória da ausência de ação social, discutida acima e projetada socialmente.

- O circuito dos beneficiários é constituído pelos participantes e suas famílias, atingidos pelo impacto do projeto. A primeira métrica percebida pelo grupo é sugerida pela disposição de pagar pelo benefício, que indica um valor anual de $\mathrm{R} \$ 456,00$. A segunda métrica está expressa no valor do impacto monetarizado de $\mathrm{R} \$ 38.040,00$ anuais, por indivíduo, que expressa o valor social atribuído às mudanças esperadas no risco social que afeta aqueles indivíduos.

No circuito organizacional, os valores apurados circulam como moeda, mas refletem a natureza híbrida das organizações sociais, associando fatos e valores para a composição do custo social sobre os esforços dos públicos constituintes. Esse circuito reflete a natureza híbrida das organizações, cujos projetos pretendem transmitir valores e produzir resultados representados nos bens públicos acessados. No circuito social dos doadores, os valores encontrados circulam como moeda e como expectativa, significando o campo das possibilidades de realização, doação, responsabilidade social e, também, de alternativas ao risco social e suas consequências. No circuito dos beneficiários, os valores apurados circulam somente como valores e atitudes, como realização do impacto, o qual não envolve o trânsito de moeda, mas pode ser apreendido, mensurado e comunicado na face simbólica da monetarização. Portanto a comensurabilidade das expressões de fato e de valor possibilita identificar, por meio da monetarização, os circuitos propostos por Zelizer em sua materialidade econômica. A interpretação dos resultados monetarizados confirma as observações de Espeland e Stevens (1998), de que a monetarização não é mera técnica, mas um exercício de significado importante na vida social dos públicos constituintes, que possibilita a explicitação de resultados intangíveis, a comparação de alternativas e a atribuição de novos significados simbólicos que valorizam os objetivos dos projetos.

\section{Conclusão}

A inclusão dos valores entre os atributos objetivamente contemplados nas avaliações de projetos locais de organizações de interesse público e nos programas de responsabilidade social possibilita superar a dicotomia fato/valor e o impacto estimado incorpora, na monetarização dos benefícios, a possibilidade de investigar as sociabilidades vinculadas à circulação da moeda, aos seus significados sociais e à sua simbologia. $\mathrm{O}$ processo de monetarização, com a apreensão de valores que tomam forma na moeda, garante a expressão da informação econômica contida nos valores reconhecidos socialmente no bem avaliado. Assim, as 4 hipóteses de monetarização que assumimos podem ser enunciadas como:

- Hipóteses experimentais, que tratam das organizações e do cálculo dos custos sociais.

H1 - Hipótese sobre a natureza institucional: assume a natureza peculiar e híbrida das organizações que atuam no espaço público. As organizações de interesse público, dotadas de uma gestão peculiar, operam em condições locais, com metas e objetivos que envolvem a reprodução de valores humanos e a produção de resultados, atendendo às expectativas, necessidades, capacidades, aos interesses e às representações dos seus públicos constituintes.

H2 - Hipótese sobre os custos sociais: assume que os custos desses projetos contemplam contribuições de todos os públicos constituintes e expressam-se como os valores disponibilizados pelas organizações nas formas diretas, indiretas, de oportunidade, orçamentárias, imobilizadas, e voluntárias, para a viabilização dos projetos.

- Hipóteses de interpretação que tratam da comensurabilidade dos indicadores e do significado social do benefício. 
H3 - Hipótese de comensurabilidade: assume que os indicadores de fato e os indicadores de valor expressam objetivamente mudanças mensuráveis referentes aos impactos pretendidos pelos projetos e garantidas, respectivamente, pelos atributos de cardinalidade e ordinalidade presentes nos fatos; e ponderação, referencial de maximização, indeterminação de causas e efeitos e unificação, presentes nos valores.

H4 - Hipótese sobre o significado social dos benefícios: assume que o processo de monetarização identifica os fatos e valores vinculados aos processos sociais avaliados, ampliando o significado do valor monetário do impacto identificado nos circuitos de troca econômica e simbólica dos bens.

Essas hipóteses sustentam a argumentação e o desenho do processo avaliativo cujos resultados, submetidos a análise estatística robusta, garantem a significância dos resultados da pesquisa, identificando um impacto mensurado que diferencia os grupos de tratamento e controle. A aplicação do processo de monetarização ainda fundado nessas hipóteses mostrou-se coerente e consistente, possibilitando identificar os "circuitos de troca" esperados entre os públicos constituintes interagentes no projeto analisado. Portanto, podemos considerar que as hipóteses acima estão validadas e mostram-se capazes de nortear a interpretação do processo avaliativo. Nesse sentido, atendem aos objetivos desta reflexão, tanto em seu aspecto teórico como enquanto ferramenta avaliativa disponível para aplicações.

É sugestivo indicar que esses argumentos podem ser testados em temas variados, alguns dos quais vêm sendo abordados pelos autores. Por exemplo, no âmbito do patrimônio artístico, cultural, material e imaterial; no campo da doação de bens, tempo, ou dinheiro para finalidades sociais; na sustentabilidade e no meio ambiente; e nas questões relativas ao idoso e aos cuidados que ele merece e requer. Embora exceda aos objetivos deste artigo, é importante ressaltar que a vinculação fato/valor como instrumento avaliativo também pode produzir aplicações consistentes em áreas nas quais as decisões devam considerar outras ponderações que afetam a monetarização. É assim, por exemplo, nas decisões de investir e nas preferências de consumo, temas que compõem o elenco de preocupações do administrador e sugerem pesquisas futuras.

Quanto a aplicações para o campo mais amplo das políticas públicas, o conceito de superação da dicotomia fato/valor é desejável, como mostram, por exemplo, os esforços de reconstrução do IDH para o exame da qualidade de vida (STIGLITZ, SEN e FITOUSSI, 2010). Entretanto, enquanto no caso dos projetos sociais locais o conceito de púbicos constituintes proporciona o padrão comparativo para aferição dos valores, no caso amplo das políticas públicas há que se considerar o termo valores sociais tomado com a maior amplitude. No Brasil, o Instituto de Pesquisa Econômica Aplicada (IPEA, 2011) e o Programa das Nações Unidas para o Desenvolvimento (PNUD, 2010), realizaram esforços nessa direção, investigando exclusivamente as hierarquias valorativas da população brasileira. Esses resultados sugerem e possibilitam que sejam examinados em comparação a eles os dados factuais de políticas públicas (p. ex., taxa de matrícula, gravidez adolescente), e possíveis decorrências economicamente quantificáveis, contribuindo para a interpretação coerente de variáveis fato/valor. Já a monetarização, no caso amplo das políticas públicas, requer outras abordagens que dialoguem com os achados da contabilidade pública, da avaliação de benefícios e das investigações de disposição para pagar.

As reflexões propostas acerca do processo de monetarização na escala local, abordada neste artigo, e seus significados almejam contribuir para a identificação e comunicação de valores humanos e das sociabilidades decorrentes de seu apreço e presentes nos processos monetarizados. É razoável supor que se os valores puderem ser ponderados e tomados em consideração nos processos avaliativos complementarmente, ao lado dos indicadores de fato, como variáveis objetivas, contribuiremos para a superação das imposições da dicotomia fato/valor, qualquer que seja sua tendência.

Retornando ao início deste artigo, às possibilidades de ruptura social, aos seus custos e às perplexidades cometidas em nome da globalização, lembramo-nos das palavras de M. Friedman (1953). Em sua defesa da positividade da economia em detrimento dos juízos valorativos, o autor afirmava que, acerca dos juízos de valor e de suas diferenças subjetivas, só restava aos homens a alternativa da luta. Almejamos contribuir para 
que essas previsões sombrias se extremadas, não se concretizem e que fatos e valores possam ser incorporados na racionalidade do diálogo global como elementos comensuráveis localmente e comunicados na dualidade imanente às faces complementares da moeda, que, inclusive, em sua origem grega, sugeria significados e simbolismos vinculados à vida social.

\section{Referências}

ABRAMOVAY, R. Entre deus e o diabo: mercado e interação humana nas ciências sociais. Tempo Social, v. 16, n. 2, p. 35-64, 2004.

AMERICAN EVALUATION ASSOCIATION. Evaluation 2011: values and valuing in evaluation. 2011. Disponível em: <www.eval.org>. Acesso em: 10 set. 2011.

APPADURAI, A. A vida social das coisas. Niterói, RJ: Universidade Federal Fluminense, 1986.

BANCO MUNDIAL. Jovens em risco no Brasil. Relatório 32310-BR. Brasília, DF: Banco Mundial, 2003. Disponível em: <http://sitesources.worldbank.org>. Acesso em: 10 out. 2011.

BEN-NER, A.; PUTTERMAN, L. Economics, values and organization. Cambridge, MA: Cambridge University Press, 1998.

CABRAL, E. H. S. Valores e espaço público: referenciais e instrumentos para a avaliação de projetos sociais. Rev. Adm. Pública, v. 45, n. 6, p. 1915-1941, nov./dez. 2011a.

Relatório de avaliação econômica e de impacto do projeto Portas Abertas. Belo Horizonte: Fundação Guimarães Rosa, 2011b.

CARRUTHERS, B.; ARIOVICH, L. Money and credit. Malden, MA: Polity, 2010.

CONTADOR, C. R. Projetos sociais: avaliação e prática. São Paulo: Atlas, 1997.

DOYLE, K. Introduction. The American Behavioral Scientist, v. 35, n. 6, p. 641-657, 1992.

DWORKIN, R. Taking rights seriously. Cambridge, MA: Harvard University Press, 1977.

ESPELAND, W.; STEVENS, M. Commensuration as a social process. Annual Reviews of Sociology, v. 24, p. 313343, 1998.

FERGUSON, N. A ascensão do dinheiro. São Paulo: Editora Planeta do Brasil, 2009.

FLIGSTEIN, N. The architecture of markets. Princeton, NJ: Princeton University Press, 2001.

FRIEDMAN, M. The methodology of positive economics. In: IL: University of Chicago Press, 1953. 3-43 p. (Ed.). Essays in positive economics. Chicago,

FURNHAM, A.; ARGYLE, M. A psicologia do dinheiro. Lisboa: Sinais de Fogo, 2000.

GRAEBER, D. Debt: the first 5,000 years. Brooklyn, NY: Melville House Publishing, 2011.

GRANOVETTER, M. Economic action and social structure: the problem of embeddedness. American Journal of Sociology, v. 91, n. 3, p. 481-510, 1985.

HONNETH, A. The struggle for recognition. The Moral Grammar of Social Conflicts. Cambridge: Polity Press, 1995. 
INSTITUTO DE PESQUISA ECONÔMICA APLICADA - IPEA. Valores e estrutura social no Brasil. 2011. Disponível em: <http://www.ipea.gov.br/agencia/images/stories/PDFs/SIPS/ 121129_ppt_valores_e_estrutura_social.pdf >. Acesso em: 10 out. 2013.

KAHNEMAN, D.; KNETSCH, J. Valuing public goods: the purchase of moral satisfaction. Journal of Environmental Economics and Management, v. 22, n. 1, p. 57-70, 1992.

MANDELBROT, B. B. The fractal geometry of nature. São Francisco, CA: Freeman, 1982.

MARTES, A. C. B. Redes e sociologia econômica. São Carlos, SP: Ed. UFSCAR, 2009.

MITCHELL, R.; CARSON, R. Using surveys to value public goods. Washington: Resources for the Future, 2005.

MONDADORE, A. P. C. et al. (Orgs.). Sociologia econômica e das finanças. São Carlos, SP: Ed. UFSCAR, 2009.

NORTH, D. Markets and other allocation systems in history: the challenge of Karl Polanyi. Journal of European Economic History, v. 6, n. 3, p. 703-716, 1977.

NUSDEO, F. Curso de economia: introdução ao direito econômico. São Paulo: Revista dos Tribunais, 2000.

OSTROM, E.; WALKER, J. (Eds.). Trust and reciprocity. Nova York: Russell Sage Foundation, 2002.

PARSONS, T.; SHILS, E. Toward a general theory of action. Cambridge, MA: Harvard University Press, 1951.

PENROSE, R. The role of aesthetics in pure and applied mathematical research. Bulletin of the Institute of Mathematics and Its Applications, v. 8, p. 9-10, 1976.

POLANYI, K. A grande transformação. Rio de Janeiro: Elsevier, 2012.

POSNER, R. Economia da Justiça. São Paulo: Martins Fontes, 2010.

PRIGOGINE, I.; STENGERS, I. La nouvelle alliance. Paris: Gallimard, 1986.

PROGRAMA DAS NAÇÕES UNIDAS PARA O DESENVOLVIMENTO - PNUD. Mostre seu valor. 2010. Disponível em: <www.mostreseuvalor.org.br>. Acesso em: 10 out. 2013.

PUTNAM, H. The collapse of the fact/value dichotomy. Cambridge, MA: Harvard University Press, 2002.

RAWLS, J. A theory of justice. Cambridge, MA: Harvard University Press, 1971.

SEN, A. Quality of life and economic evaluation. Academia Sinica Economic Papers, v. 25, n. 3, p. 269-316, 1997.

1999. . The possibility of social choice. Nobel Lecture. The American Economic Review, v. 89, n. 3, p. 349-378,

SERVA, M.; DIAS, T.; ALPERSTEDT, G. D. Paradigma da complexidade e teoria das organizações: uma reflexão epistemológica. Revista de Administração de Empresas, v. 50, n. 3, p. 276-287, 2010.

SIMMEL, G. The philosophy of money. Nova York: Routledge, 1978.

SMELSER, N.; SWEDBERG, R. The handbook of economic sociology. Nova York: Russel Sage, 2005.

STEINER, P.; VATIN, F. Traité de sociologie économique. Paris: Presses Universitaires de France, 2009.

STIGLITZ, J. Simple formulae for optimal income taxation and the measurement of inequality. In: BASU, K.; KANBUR, R. (Eds.). Arguments for a better world: essays in honor of Amartya Sen. Oxford: Oxford University Press, 2009. v. 1, 535-566 p. 
; SEN, A.; FITOUSSI, J.-P. Report by the Commission on the Measurement of Economic Performance and Social Progress. Paris: République Françáise, 2010. Disponível em: 〈www.stiglitz-sen-fitoussi.fr〉. Acesso em: 20 out. 2011.

VALENTIM, J.; PRADO, M. Social discount rates. Reports of IMT Lucca Institute for Advanced Studies, 2008. Disponível em: <http://ssrn.com/abstract=1113323〉. Acesso em: 10 jan. 2011.

VEYNE, P. Acreditavam os gregos em seus mitos? São Paulo: Brasiliense, 1983.

VINHA, V. The social meaning of money. Nova York: Basic Books, 1994.

Polanyi e a nova sociologia econômica: uma aplicação contemporânea do conceito de enraizamento social. Econômica, v. 3, n. 2, p. 207-230, 2003.

ZELIZER, V. Monétisation et la vie sociale. Le Portique, v. 19, p. 2-11, 2007. 